\title{
Noticias 2017
}

Lic. María Angélica Rozas Rozas Alvarez

Instituto de Investigaciones Museológicas y Artísticas / Universidad Ricardo Palma mrozas@urp.edu.pe
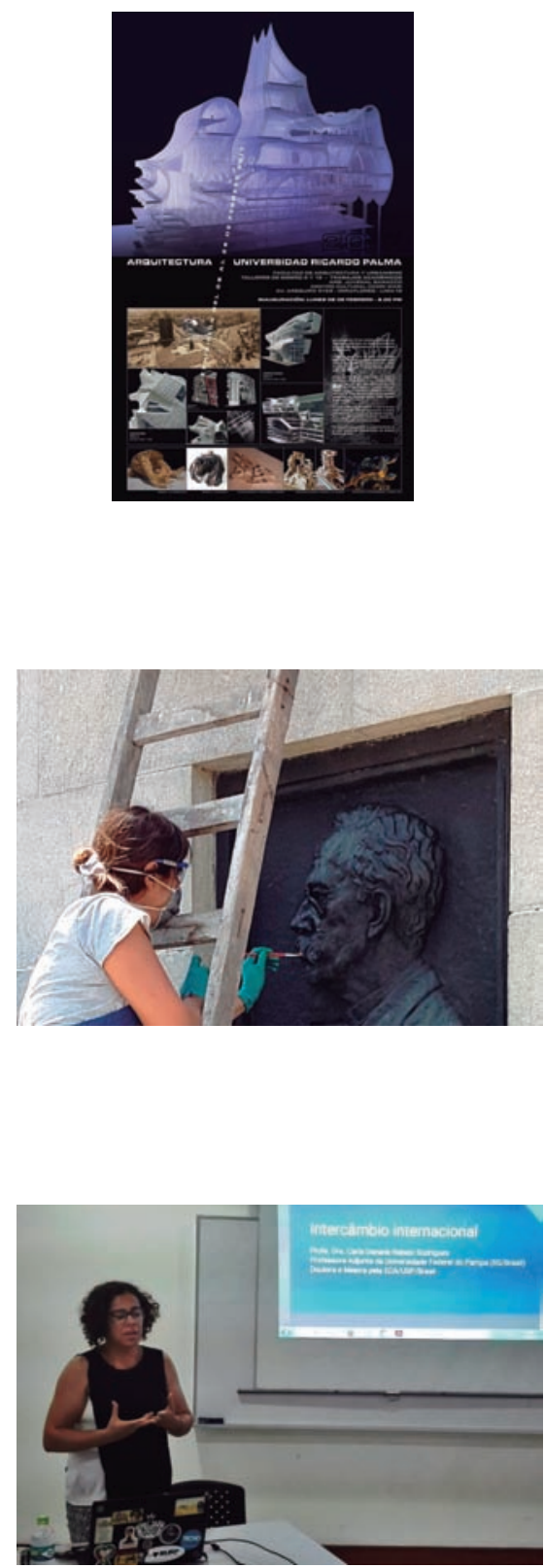

Exposición Talleres de Diseño V y XV 2017 organizada por la Facultad de Arquitectura y Urbanismo de la Universidad Ricardo Palma. Como todos los años, se exhibió una selección de los mejores proyectos académicos de los alumnos, dirigidos a cargo del arquitecto Juvenal Baracco durante los semestres 2016-I y 2016-II, de los niveles de enseñanza Básico I-II (Taller 5), [Huaca] Espacio y Territorio, [Manzana] Ciudad y Evento, Metáfora y Performance, Nivel Vertical (Taller 15). La muestra se presentó del 8 al 28 de febrero en la Galería de Artes Visuales.

Por encargo del Dr. Iván Rodríguez Chávez, rector de nuestra universidad, el Instituto de Investigaciones Museológicas y Artísticas tuvo a su cargo el Proyecto de Conservación y Restauración del Mausoleo de Ricardo Palma, que se encuentra ubicado en el cementerio Presbítero Maestro. Para este trabajo se contó con la colaboración de la Beneficencia Pública de Lima y la participación del grupo de investigación, conservación y restauración Kullasiri, quienes durante el mes de marzo estuvieron realizando trabajos de limpieza, conservación y restauración en dicho lugar.

El Instituto de Investigaciones Museológicas y Artísticas, en coordinación con la Asociación Nacional de Museólogos del Perú, organizaron el conversatorio "Políticas Culturales, sus avances y limitaciones para la producción cultural del país”, a cargo de la Dra. Carla Rabelo Rodríguez, profesora adjunta de la Universidad Federal do Pampa, realizada el 15 de marzo en las instalaciones del Centro Cultural Ccori Wasi. 
El 27 de abril se llevó a cabo, en las instalaciones de la Galería de Artes Visuales, la presentación del libro Mariátegui. Biografía Ilustrada, de Servais Thissen. Los comentarios estuvieron a cargo de María Julia Méndez y Ricardo Portocarrero.

El 28 de abril, el Instituto de Investigaciones Museológicas y Artísticas, junto a otros especialistas, como Emily Floyd y Verónica Muñoz-Najar, organizó el ciclo de conferencias Diálogos de Arte, en el que jóvenes historiadores del arte peruanos y extranjeros presentaron sus investigaciones sobre historia del arte. Este evento se realizó con motivo de la reunión en Perú de LASA 2017 (Asociación de Estudios Latinoamericanos). El evento se llevó a cabo en el auditorio del Centro Cultural Ccori Wasi.

El 30 de mayo tuvo lugar la disertación de la tesis El Museo de Sitio Arturo Jiménez Borja-Puruchuco, Diagnóstico y Lineamientos para mejorar su propuesta museográfica, del bachiller Rodrigo Amorós Figueroa, egresado de la maestría en Museología y Gestión Cultural. En la foto, de izquierda a derecha, Dr. Carlos Bancayan Oré, Mg. Anita Tavera Tavera, Dr. Elio Martuccelli Casanova, Mg. Rodrigo Amorós Figueroa, Mg. Miguel Ángel Vidal Trujillo y Dr. Alfonso Castrillón Vizcarra.

Del 4 al 17 de junio se llevó a cabo el seminario taller Estrategias para enseñar con objetos y colecciones de museos, organizado por el Instituto de Investigaciones Museológicas y Artísticas de la Universidad Ricardo Palma, en coordinación con la maestría de Museología y Gestión Cultural de la URP y la Fundación Fullbright. El curso fue dirigido por el Dr. William Crow, docente de la Universidad de Nueva York y educador a cargo del Museo Metropolitano de Arte de Nueva York, Estados Unidos. En la foto, de izquierda a derecha, Dr. Alfonso Castrillón Vizcarra, Dr. William Crow y Sr. Henry Harman Guerra.
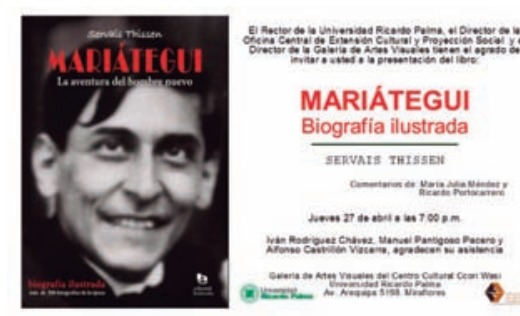

MARIÁTEGUI

Biografia ilustrada

senvars THIsgest

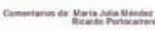

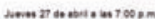

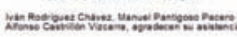

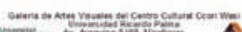
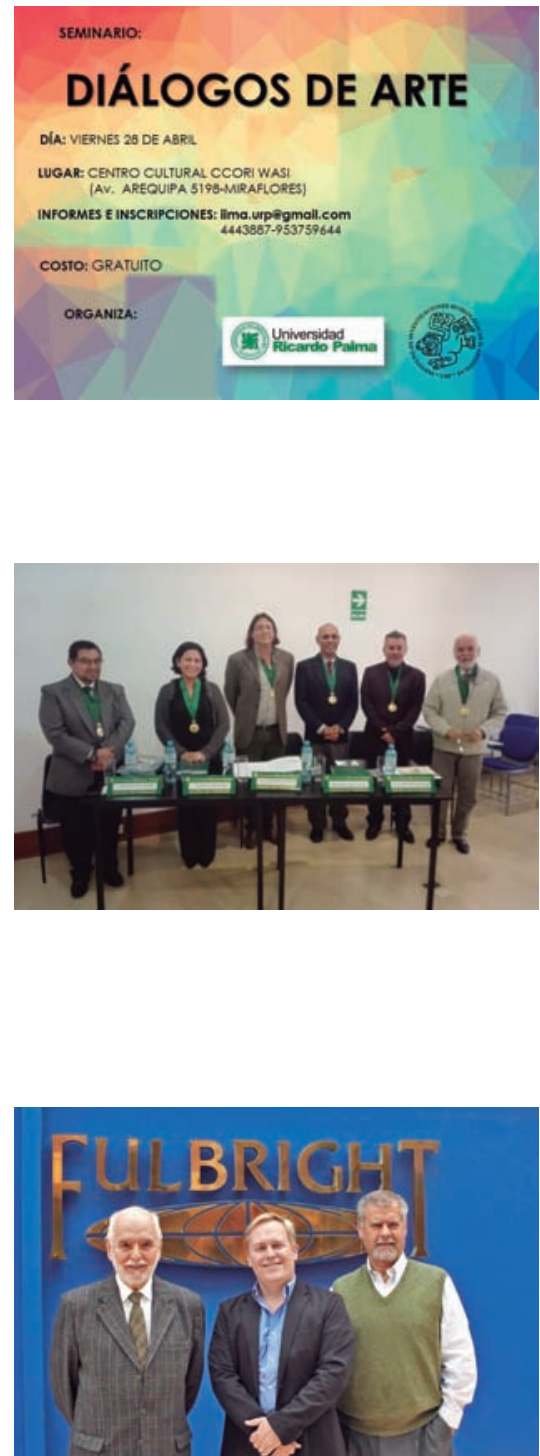

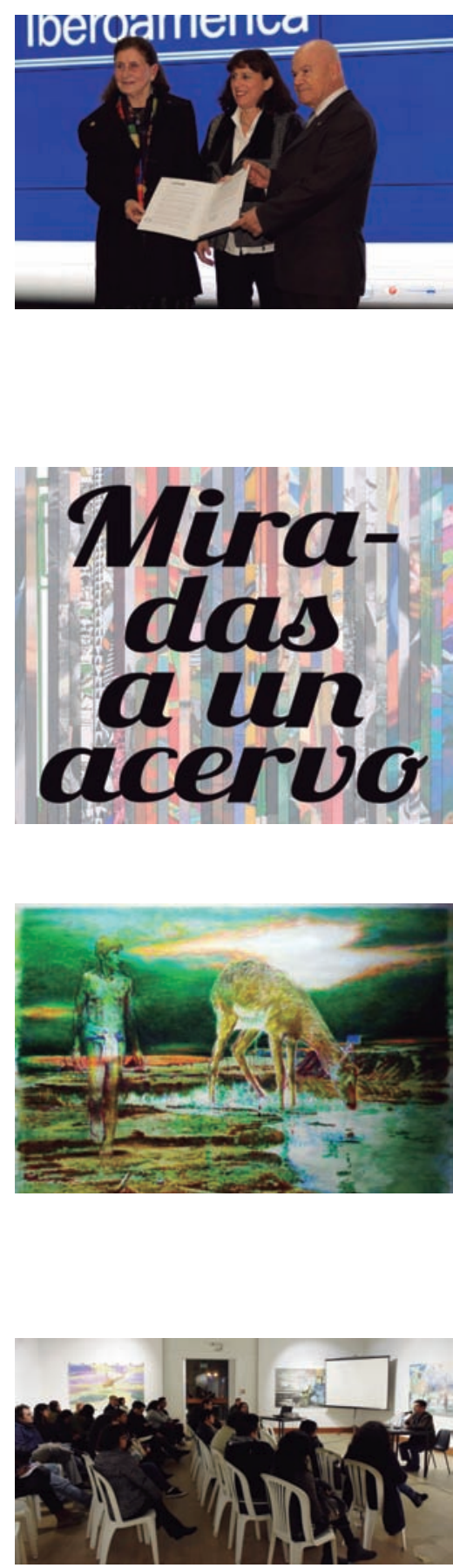

El 28 de junio se cumplieron diez años de la firma de la Declaración de la Ciudad de Salvador, Bahía, documento en el que se crea el Observatorio Iberoamericano de Museos del Programa Ibermuseos. En el marco de esta celebración, se le hizo entrega del acta de inscripción en el Registro Nacional de Museos Públicos y Privados al Museo de Historia Natural Vera Alleman Haeghebaert, de la Universidad Ricardo Palma. En la foto, de izquierda a derecha: Dra. Vera Alleman Haeghebaert, directora del Museo de Historia Natural; Dra. Luisa Vetter, directora general de museos del Ministerio de Cultura, y Dr. Iván Rodríguez Chávez, rector de la Universidad Ricardo Palma.

Miradas a un Acervo: 20 años, organizada por la Galería de Artes Visuales de la Universidad Ricardo Palma, en conmemoración de su vigésimo aniversario, con la curaduría de Alfonso Castrillón Vizcarra. La muestra recorre los 20 años de trabajo expositivo de la Galería de Artes Visuales, desde su creación en 1997 hasta la actualidad, y en la que se pueden apreciar diversos estilos y técnicas de trabajo de artistas peruanos y extranjeros. La exposición estuvo desde el 7 de julio al 30 de agosto.

El Pulmón de Dios (para llevar), muestra individual del artista franco-peruano Hervé R. V. Miloux, quien vive desde hace diez años en Iquitos, escenario que lo inspira a indagar de una manera personal a través de diferentes técnicas pictóricas en este referente amazónico, en sus paisajes, colores y texturas; en todo lo que simboliza la Amazonía. La exposición estuvo desde el 8 de septiembre hasta el 1 de octubre.

Del 11 al 15 de setiembre se llevó a cabo el CursoTaller Introducción al Diseño de Exposiciones, organizado por el Instituto de Investigaciones Museológicas y Artísticas de la Universidad Ricardo Palma, en coordinación con la Maestría de Museología y Gestión Cultural de la URP. El curso fue dirigido por el Mg. Rodrigo Witker Barra, docente de la Universidad Autónoma de Puebla, México, museólogo en el Instituto Nacional de Antropología e Historia (INAH) y museógrafo del Museo de Arocena, México. 
Amentes, muestra organizada por el Hospital Víctor Larco Herrera, la Embajada de Francia en el Perú y la Galería de Artes Visuales de la Universidad Ricardo Palma, en la que se exhibió parte del acervo documental y científico del hospital, además de las obras de la pinacoteca Honorio Delgado, la cual guarda los trabajos de los talleres de expresión artística para los pacientes del hospital que dirigió el doctor Honorio Delgado. La exposición se presentó del 6 de noviembre al 1 de noviembre.

Los días 24 y 25 de octubre se desarrolló el conversatorio Terapia por el Arte en Esquizofrenia, organizado por la Galería de Artes Visuales, el Hospital Larco Herrera y el Instituto de Investigaciones Museológicas y Artísticas de la Universidad Ricardo Palma, en el marco de la exposición Amentes.

Lima Design Week 2017, plataforma dedicada al diseño, presentó su quinta edición, en la que estuvieron invitados países como Costa Rica, con la presencia de destacados profesionales del diseño, así como España, cuyo tema fue la identidad española, a cargo del arquitecto español José Ángel Cicero Torre. LDW 2017 estuvo organizado por Diori, Diseño \& Organización Integral, y fue patrocinado por la Universidad Ricardo Palma y Trodat Totec Group. Se llevó a cabo del 7 al 19 de noviembre en la Galería de Artes Visuales y las instalaciones del Centro Cultural Ccori Wasi.
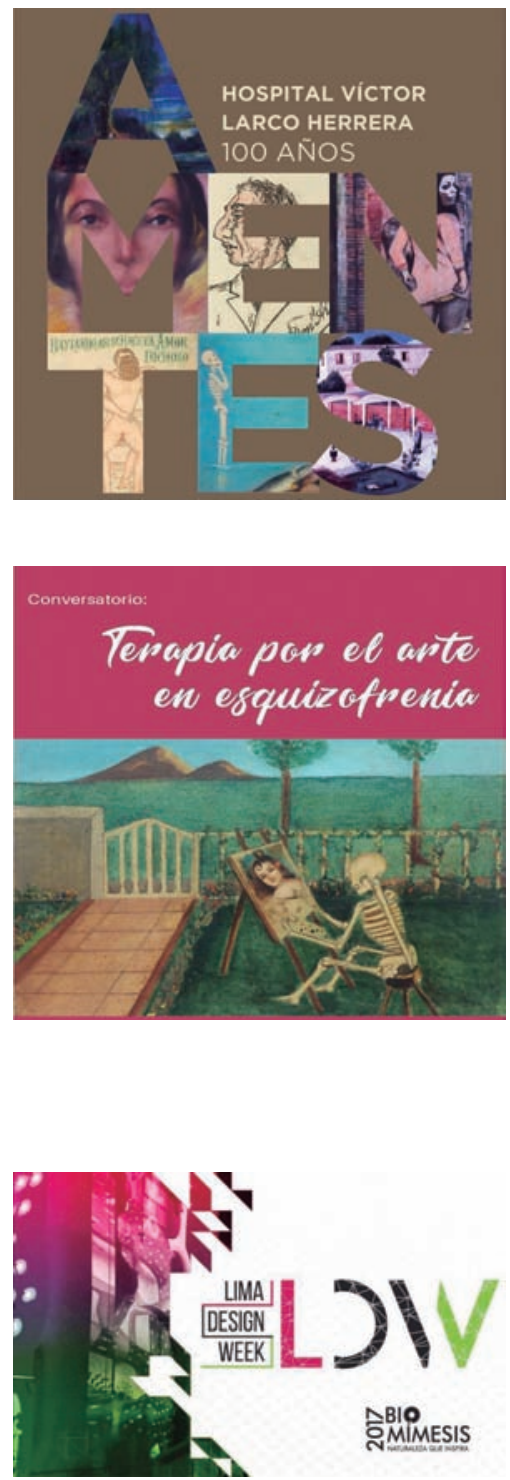